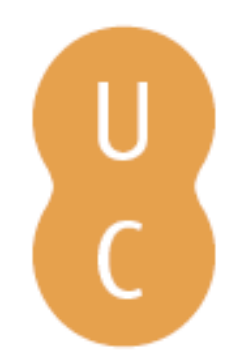

\title{
nombalina
}

\section{Equidade em saúde: o papel das condições socioeconómicas e dos cuidados de saúde primários}

\author{
Autor(es): $\quad$ Santana, Paula; Ferreira, Pedro Lopes \\ Publicado por: Imprensa da Universidade de Coimbra \\ URL \\ persistente: URI:http://hdl.handle.net/10316.2/43491 \\ DOI: $\quad$ DOI:https://doi.org/10.14195/978-989-26-1343-7_21 \\ Accessed : $\quad$ 26-Apr-2023 12:06:52
}

A navegação consulta e descarregamento dos títulos inseridos nas Bibliotecas Digitais UC Digitalis, UC Pombalina e UC Impactum, pressupõem a aceitação plena e sem reservas dos Termos e Condições de Uso destas Bibliotecas Digitais, disponíveis em https://digitalis.uc.pt/pt-pt/termos.

Conforme exposto nos referidos Termos e Condições de Uso, o descarregamento de títulos de acesso restrito requer uma licença válida de autorização devendo o utilizador aceder ao(s) documento(s) a partir de um endereço de IP da instituição detentora da supramencionada licença.

Ao utilizador é apenas permitido o descarregamento para uso pessoal, pelo que o emprego do(s) título(s) descarregado(s) para outro fim, designadamente comercial, carece de autorização do respetivo autor ou editor da obra.

Na medida em que todas as obras da UC Digitalis se encontram protegidas pelo Código do Direito de Autor e Direitos Conexos e demais legislação aplicável, toda a cópia, parcial ou total, deste documento, nos casos em que é legalmente admitida, deverá conter ou fazer-se acompanhar por este aviso.

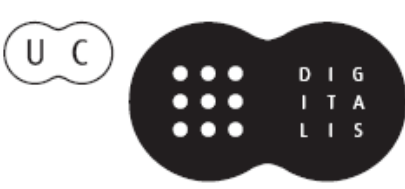




\section{FERNANDA CRAVIDÃO}

\section{IÚCIO CUNHA}

PAULA SANTANA

\section{NORBERTOSANTOS}

(ORG.)

\section{ESPAÇOS E TEMPOS EM GEOGRAFIA}

HOMENAGEM A ANTÓNIO GAMA

IMPRENISA DÁ UNIVERSIDADE DE COIMBRA COIMBRA UNIVERSITY PRESS

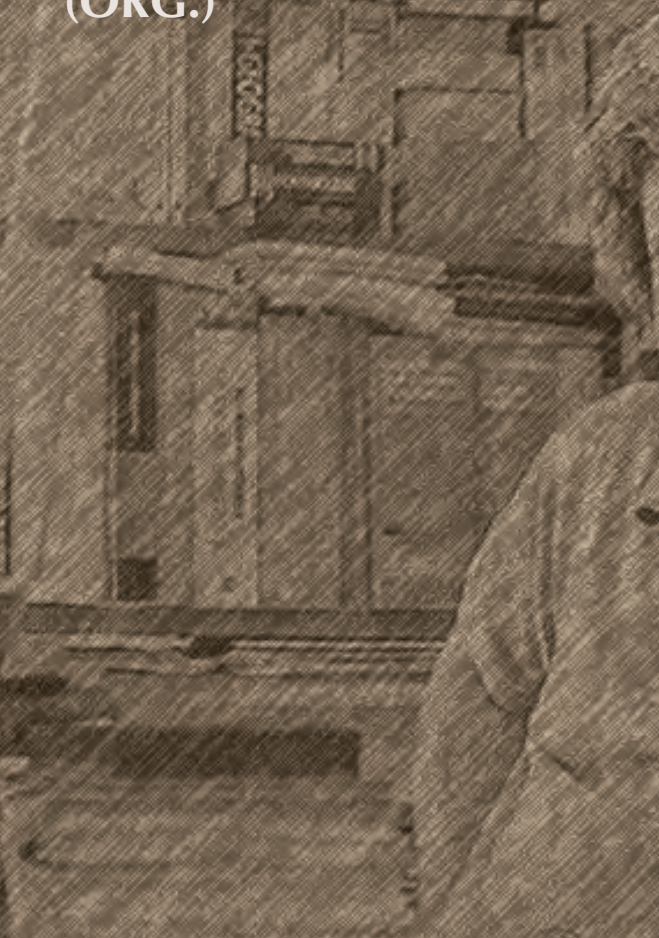




\title{
EQUIDADE EM SAÚDE. O PAPEL DAS CONDIÇÓES SOCIOECONÓMICAS E DOS CUIDADOS DE SAÚDE PRIMÁRIOS
}

\author{
Paula Santana \\ CEGOT e Departamento de Geografia e Turismo \\ da Universidade de Coimbra \\ Pedro Lopes Ferreira \\ CEISUC e Faculdade de Economia \\ da Universidade de Coimbra
}

Nos últimos vinte anos (entre 1991 e 2011) a saúde da população portuguesa residente nos municípios do Continente melhorou consideravelmente (Santana e Freitas, 2015b) verificando-se, ainda, a redução das desigualdades entre municípios na mortalidade prematura, nas condições da habitação, escolaridade e no acesso geográfico aos cuidados de saúde (hospitais e centros de saúde) (Freitas e Costa, 2015). Em sentido oposto, outros indicadores revelam o aumento da vulnerabilidade de alguns territórios expressa, por exemplo, no aumento do envelhecimento, dos idosos a viver sós e no desemprego (Freitas e Costa, 2015).

A redução das desigualdades sociais e geográficas é uma das prioridades dos governos democráticos, sendo essencial garantir o acesso tempestivo da população a serviços públicos de qualidade. A equidade vai além do mero combate das desigualdades; exige um esforço intersetorial na análise, avaliação e redução das vulnerabilidades a que certos grupos populacionais estão 
expostos (Koivusalo et al., 2007), que resultam de determinantes sociais da saúde ("causa das causas") (Marmot et al., 2008), incluindo os cuidados de saúde de qualidade.

Este texto tem como objetivo i) identificar condiçôes do contexto que influenciam a saúde da população e como evoluíram nos últimos vinte anos em Portugal Continental; ii) analisar o papel dos Cuidados de Saúde Primários (CSP) na equidade em saúde e iii) avaliar a satisfação dos utilizadores com os CSP.

O texto é dividido em quatro partes. É iniciado com um enquadramento geral ao Sistema de Saúde Português, dando destaque aos CSP e à relevância da avaliaçáo dos serviços. Na segunda parte são apresentadas fontes e métodos de análise. A terceira e quarta partes apresentam os resultados das análises das características sociais e de acesso aos cuidados de saúde e, ainda, a avaliação dos utilizadores da qualidade dos CSP.

\section{Contexto}

Qualquer sistema de saúde inclui todas as atividades, todos os atores, instituiçôes e recursos cujo objetivo principal é promover, restaurar ou manter a saúde dos cidadãos (WHO, 2000, 2007). Relativamente a Portugal, no início da década de 70 do século passado, a situação do sistema de saúde pode ser caracterizada por um baixo financiamento dos serviços públicos de saúde e pela existência de indicadores socioeconómicos e de saúde muito desfavoráveis (Santana 2014), mesmo quando comparados com os de outros países da Europa Ocidental. A oferta de cuidados era muito fragmentada e variada, com hospitais do Estado e das Misericórdias, postos médicos dos Serviços Médico Sociais da Previdência, Serviços de Saúde Pública, médicos municipais, e serviços especializados de saúde materno-infantil, tuberculose e doenças psiquiátricas. Para além desta oferta existia também um setor médico privado, em especial na área dos cuidados ambulatórios (OPSS, 2001, 2002).

Mais tarde, em 1971, sob a responsabilidade de Gonçalves Ferreira, então Secretário de Estado da Saúde e Assistência, os Serviços Médico Sociais atrás 
referidos passaram a denominar-se Centros de Saúde, constituindo, para muitos, essa decisão um primeiro embriấo de um Serviço Nacional de Saúde (SNS), embora as circunstâncias políticas e sociais de então o tivessem impedido de levar a cabo essa decisão.

Só a partir de 25 de abril de 1974 e da aprovação da Constituição da República Portuguesa (CRP) em 2 de abril 1976 é que o Estado Português reconhece o direito à saúde, definindo no art. $64 .^{\circ}$ da CRP que "o direito à proteção da saúde é realizado pela criação de um Serviço Nacional de Saúde universal, geral e gratuito...”. No entanto, fazendo parte integrante do processo de democratização política e social por que passava o país, só em 15 de setembro de 1979 é que a Assembleia da República aprova a Lei n.o 56/79 que criou o SNS, englobando todos os cuidados de saúde de prevençáo da doença, de diagnóstico e tratamento dos doentes e de reabilitação.

Rapidamente se assiste a uma notável cobertura geográfica dos serviços de saúde e se efetiva, por parte do Estado, a sua responsabilidade na proteção da saúde, individual e coletiva.

Em 1990, a Lei de Bases da Saúde (Lei no 48/90) reestrutura o SNS, tendo como objetivos "ser universal quanto à população abrangida; prestar integralmente cuidados globais ou garantir a sua prestação; ser tendencialmente gratuito para os utentes, tendo em conta as condiçôes económicas e sociais dos cidadãos; garantir a equidade no acesso dos utentes com o objetivo de atenuar os efeitos das desigualdades económicas, geográficas e quaisquer outras no acesso aos cuidados; ter organização regionalizada e gestão descentralizada e participada (Koivusalo et al., 2007).

\section{Cuidados de Saúde Primários}

Os cuidados de saúde primários pretendem afirmar-se como a primeira e a principal forma de contacto dos cidadáos com o sistema de saúde. Isso é assumido pela reforma dos cuidados primários em curso, constatada que foi a necessidade de uma profunda mudança organizacional. 
O Observatório Português dos Sistemas de Saúde (OPSS) acompanhou a reorganização dos cuidados de saúde primários e considerou-a um contributo importante para a obtenção de ganhos em saúde (OPSS, 2008). Este processo passou pela criação de Unidades de Saúde Familiar (USF), pequenas equipas multiprofissionais e auto-organizadas, dispondo de autonomia funcional e técnica e sujeitas a uma contratualização de carteira básica de serviços, com meios de diagnóstico descentralizados e um sistema retributivo facilitador de uma maior produtividade, acessibilidade e qualidade. Foram também criados Agrupamentos de Centros de Saúde (ACeS), entidades organizativas e de gestão a um nível superior ao das USF, que também integram as antigas estruturas de CSP, agora designadas por Unidades de Cuidados de Saúde Personalizados (UCSP).

A abertura da primeira fase de candidaturas à criação de USF teve início no dia 1 de março de 2006, prevendo-se, na altura, o envolvimento de cerca de vinte e dois mil profissionais e de duas mil unidades de prestação de cuidados. Em 7 de março de 2016 (dados da ACSS) existem 241 USF-A e 208 USF-B a que correspondem 2.936 médicos de família (ponderados pela dimensão da lista) e a 5.210.785 utentes com médico de família atribuído. A distribuição é, no entanto, muito assimétrica, revelando desigualdades geográficas no acesso a estes serviços, que podem comprometer a equidade em saúde (Figura 1). Mais ainda, se tivermos em conta as 411 UCSP existentes que envolvem 2.220 médicos de família ponderados e 3.551.819 utentes.

Em recente estudo (Ferreira e Raposo, 2015), as USF apresentaram, de uma forma sistemática, maior satisfação face às UCSP e, dentro daquelas, os modelos B das USF foram também premiados com maior satisfação face aos modelos A. Isto levanta um outro tipo de iniquidade, sendo também difícil de aceitar que cidadãos portugueses tenham acesso a cuidados de saúde primários distintos, em relação aos quais manifestam níveis de satisfação muito diferentes. 


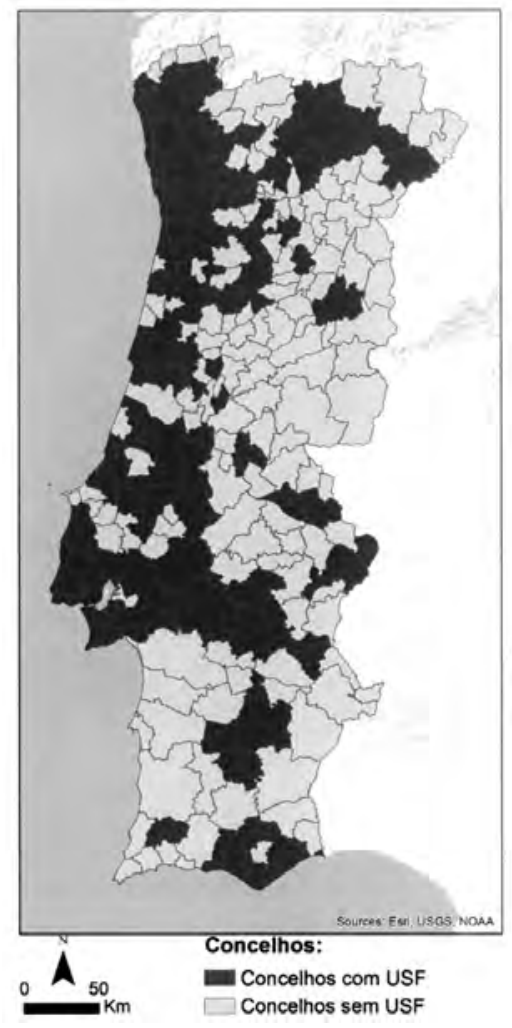

Figura 1

Concelhos com USF e outras UCSP

Fonte: Elaborado a partir de informação disponibilizada pela ACSS

O próprio primeiro Memorando de Entendimento emitido em 3 de maio de 2011 pela troika (i.e., Fundo Monetário Internacional, Banco Central Europeu e União Europeia) no início da "intervenção" a que Portugal esteve sujeito, já aconselhava o aumento do número de USF contratualizadas e, mais recentemente, um relatório da OCDE (OECD, 2015), após considerar inovador e impressionante o nosso sistema de CSP, quando comparado com o de outros países da OCDE, sugere que Portugal deve definir uma data para a transformação de todas as UCSP em USF e/ou introduzir nas UCSP incentivos de qualidade/desempenho existentes nas USF. 


\section{Satisfação dos utilizadores dos Cuidados de Saúde Primários}

É reconhecido o papel dos serviços prestadores de cuidados de saúde na satisfação das necessidades e das expectativas dos seus utilizadores, quer no que respeita aos aspetos técnicos dos cuidados quer aos interpessoais (Campbell et al., 2000; Donabedian, 1988). Além disto, em época de grandes mudanças na sociedade baseada no conhecimento, de aumentos da despesa com a saúde e de grandes limitaçóes orçamentais, é cada vez mais importante que a prestação de cuidados satisfaça as necessidades subjetivas dos doentes. Por isso, a avaliação da satisfação dos utilizadores é hoje em dia reconhecida como um valor a adicionar a outras medidas de resultado como o estado de saúde ou a qualidade de vida (Debono e Travaglia, 2009; Grol et al., 2000).

A satisfaçáo pode então ser enquadrada quer em termos das exigências das sociedades atuais, na ótica dos direitos dos cidadáos e seu envolvimento no sistema de saúde, quer como uma forma de avaliar o desempenho das organizaçóes de saúde, quer mesmo como um meio de prestar contas e de exercer a transparência. Já nos anos 80 do século passado, Hannu Vuori defendia que a satisfaçáo dos doentes devia ser incluída nos processos de garantia de qualidade, que os doentes eram perfeitamente capazes de avaliar a qualidade dos cuidados e que esta avaliação podia ser medida (Vuori, 1987).

Por isso, atualmente a satisfaçáo dos doentes é considerada uma componente indispensável à avaliação da qualidade dos cuidados e há evidência da sua correlação com os próprios resultados em saúde. Por outro lado, qualquer organização está inserida num ambiente com o qual interage permanentemente, promovendo constantes trocas de bens e serviços. Nos serviços de utilidade pública, tais como as instituiçóes sociais, de saúde e de educaçáo, este intercâmbio deve ainda ser mais acentuado em consequência da forte pressáo e da crescente procura de participaçáo por parte da sociedade civil (Ferreira e Raposo, 2015). 


\section{Dados e métodos}

Esta secção é dividida em duas partes. Uma relativa aos indicadores de contexto, correspondendo aos municípios de residência, e outra à satisfação com os CSP.

2.1 Indicadores demográficos, socioeconómicos, de acesso e condição geral de saúde

Foi recolhido um conjunto de indicadores, em 1991 e 2011, para cada concelho do Continente (Quadro I).

\section{Quadro I}

Indicadores socioeconómicos e demográficos utilizados e respectivas fontes

\begin{tabular}{|l|l|l|}
\hline \multicolumn{1}{|c|}{ Indicador } & \multicolumn{1}{c|}{ Dimensáo } & \multicolumn{1}{c|}{ Fonte } \\
\hline Índice de privação material & Socioeconómica & www.ine.pt \\
\hline Idosos que vivem sós (\%) & Socioeconómica & www.ine.pt \\
\hline $\begin{array}{l}\text { Proporçáo de idosos na } \\
\text { população total (\%) }\end{array}$ & Socioeconómica & www.ine.pt \\
\hline Densidade populacional (hab/km²) & Demográfica & www.ine.pt \\
\hline Índice de saúde da população & $\begin{array}{l}\text { Condiçáo geral } \\
\text { de saúde }\end{array}$ & http://saudemunicipio.uc.pt \\
\hline $\begin{array}{l}\text { Taxa de mortalidade prematura } \\
(100.000 h a b)\end{array}$ & $\begin{array}{l}\text { Condição geral } \\
\text { de saúde }\end{array}$ & www.ine.pt \\
\hline $\begin{array}{l}\text { Acessibilidade geográfica aos } \\
\text { hospitais (min). }\end{array}$ & Acesso a serviços & http://saudemunicipio.uc.pt \\
\hline
\end{tabular}

Alguns destes indicadores foram disponibilizados já calculados (e.g. índice de saúde da população, acessibilidade geográfica aos hospitais, densidade populacional); outros foram transformados em percentagem (e.g. proporção de idosos na população total e idosos que vivem sós) ou taxa (taxa de mortalidade prematura de indivíduos com menos de 70 anos). Adicionalmente, procedeu-se à construção do Índice de Privação Material (IPM) dos municípios, calculado normalizando e somando três variáveis censitárias: a taxa de analfabetismo, a taxa de desemprego e a percentagem de alojamentos familiares de residência habitual sem retrete. Seguiu-se o método proposto por Carstairs e Morris 
(1990), em que valores superiores a 0 significam privaçáo superior à média do Continente, enquanto municípios com resultados negativos apresentam melhores condiçóes que a média.

\section{Análise estatística}

As áreas de risco potencial resultantes dos fatores socioeconómicos foram identificadas através da análise de dependência e heterogeneidade espacial. Os indicadores selecionados foram submetidos a uma análise exploratória para identificar a existência de auto correlação espacial, através do índice de auto correlação espacial de Moran (I de Moran Global e Local). Verificando-se uma auto correlaçáo espacial estatisticamente significativa, foram identificados os clusters espaciais de valores similares positivos e negativos, através da análise espacial local (LISA) (Anselin, 1995). Sobrepondo estes clusters espaciais (positivos e negativos) foi possível identificar a frequência com que determinados municípios faziam parte de aglomerados espaciais com significativamente melhores ou piores condiçóes.

Para avaliar possíveis associaçôes estatísticas entre os indicadores em estudo (i.e., entre, por um lado, os quintis de privação material e os restantes indicadores de contexto e, por outro, o índice de satisfação dos utilizadores e indicadores de contexto), recorreu-se ao coeficiente de determinação, às correlaçóes lineares de Pearson e respetivos valores de significância.

\section{Dados de satisfação}

Os dados de satisfação utilizados neste texto provêm de um estudo realizado em junho de 2015 após convite da Administração Central do Sistema de Saúde (ACSS) ao CEISUC para determinar o grau de satisfaçáo dos utilizadores com os cuidados prestados por todas as USF e por algumas UCSP do país, aleatoriamente selecionadas (Ferreira e Raposo, 2015). Pretendeu-se também 
efetuar uma análise comparativa de âmbito nacional, dos cuidados de saúde primários, entre unidades de saúde com o mesmo modelo organizacional e unidades de saúde com modelos diferentes. Foram assim consideradas todas as 201 USF-A e as 192 USF-B entáo existentes e uma amostra aleatória de 51 UCSP, perfazendo um total de 444 unidades funcionais de prestação de cuidados primários de saúde.

O questionário utilizado para a recolha da informação foi baseado no questionário Europep, um questionário europeu para cuja conceção e validação contribuímos desde 1994 (Grol et al., 2000). Mede essencialmente quatro dimensôes: (1) cuidados médicos; (2) cuidados não médicos; (3) organizaçâo dos cuidados; e (4) qualidade das instalaçôes. Nos cuidados médicos são abordadas ambas as componentes interpessoais e técnicas dos médicos de família e na dimensão referente aos cuidados não médicos são abordados os cuidados de enfermagem e a atenção prestada pelos secretários clínicos. Por fim, na organizaçáo dos cuidados sáo analisadas a acessibilidade e os serviços prestados em geral.

Deste questionário é possível obter um conjunto de dimensōes e subdimensões apresentadas no Quadro II e obtidas estatisticamente através de análise fatorial pelo método das componentes principais após uma rotação varimax.

\section{Quadro II}

Dimensôes e subdimensôes de monitorização da satisfação

$$
\begin{aligned}
& \text { I Cuidados médicos } \\
& \text { - Componente interpessoal } \\
& \text { - Componente técnica } \\
& \text { II Cuidados não médicos } \\
& \text { - Enfermagem } \\
& \text { - Secretariado clínico } \\
& \text { - Acessibilidade } \\
& \text { - Serviços prestados }
\end{aligned}
$$

O número total de questionários entregues aos utilizadores foi de 58.846, tendo este projeto obtido uma enorme taxa de resposta: $89,3 \%$ para as USF e $90,1 \%$ para as UCSP. 


\section{Das condiçóes de contexto e resultados em saúde}

Conforme se pode observer nos mapas das Figuras 2 e 3, as condições gerais de saúde melhoraram consideravelmente entre 1991 e 2011 (Santana e Freitas, 2016b), sendo possível observar a diminuição, generalizada, das taxas de mortalidade prematura e aumento dos valores do Índice de Saúde da População (para informação mais detalhada vide Santana e Freitas, 2016 a; Santana e Freitas, 2016 b). O padrão geográfico de ambos é semelhante, caracterizando-se por melhores valores nos municípios da faixa litoral entre o Minho Litoral e Lisboa (com algumas exceçóes, onde se incluem os municípios de Lisboa e Porto).

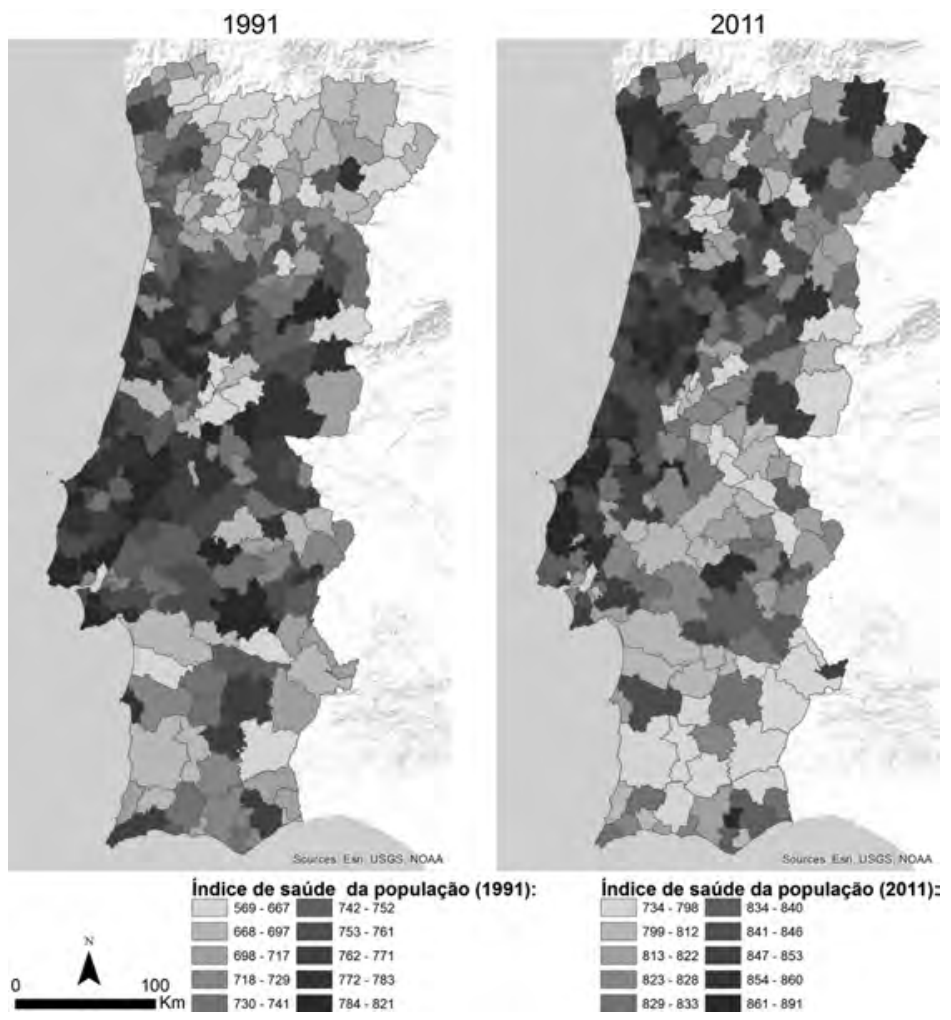

Figura 2

Índice de Saúde da População, em 1991 e 2011

Fonte: GeoHealthS, 2016 


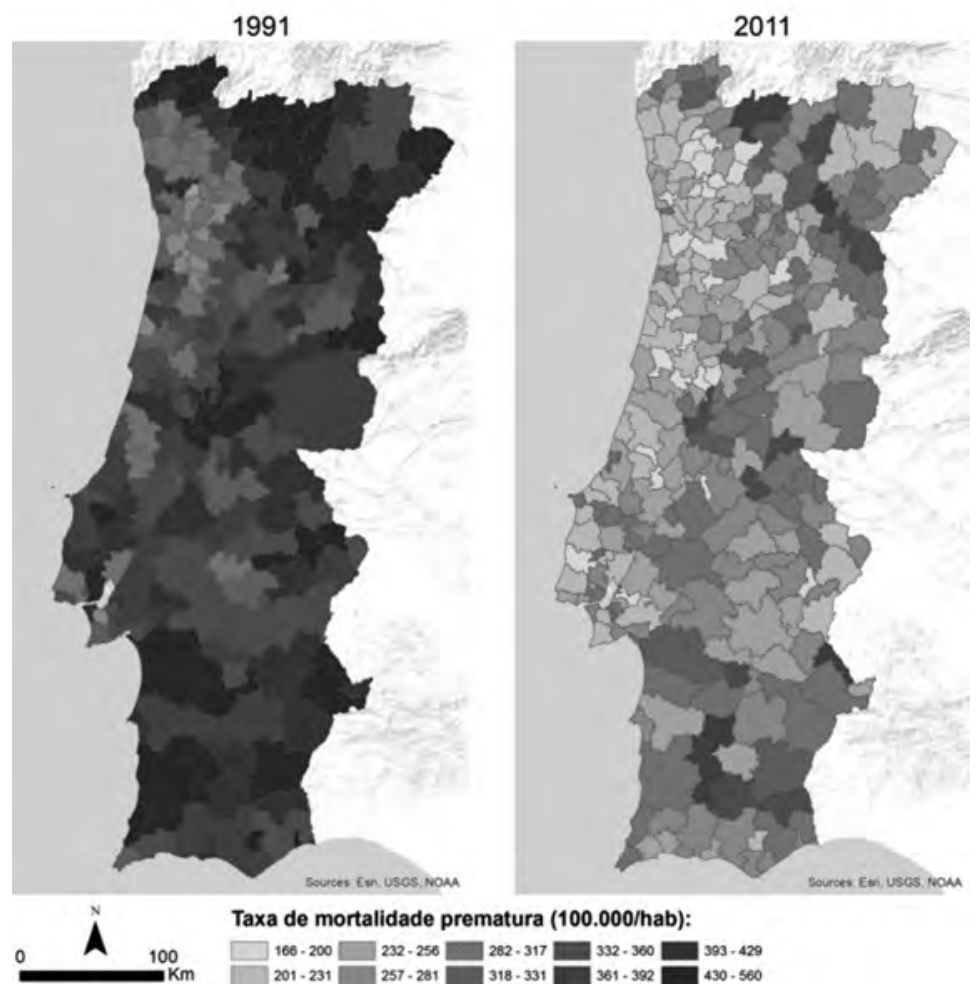

Figura 3

Taxa de mortalidade prematura, em 1991 e 2011

Fonte: Elaborado a partir de INE, Portugal, 1991 e 2001

Relativamente aos mais idosos, os indicadores socioeconómicos relacionados com o envelhecimento da população revelam um aumento da proporção de idosos na população total (Figura 4) e de idosos a viverem sós (Figura 5), destacando-se os concelhos de Porto e Lisboa por apresentarem características mais próximas às dos municípios do interior que aos restantes concelhos da respetivas áreas metropolitanas. 

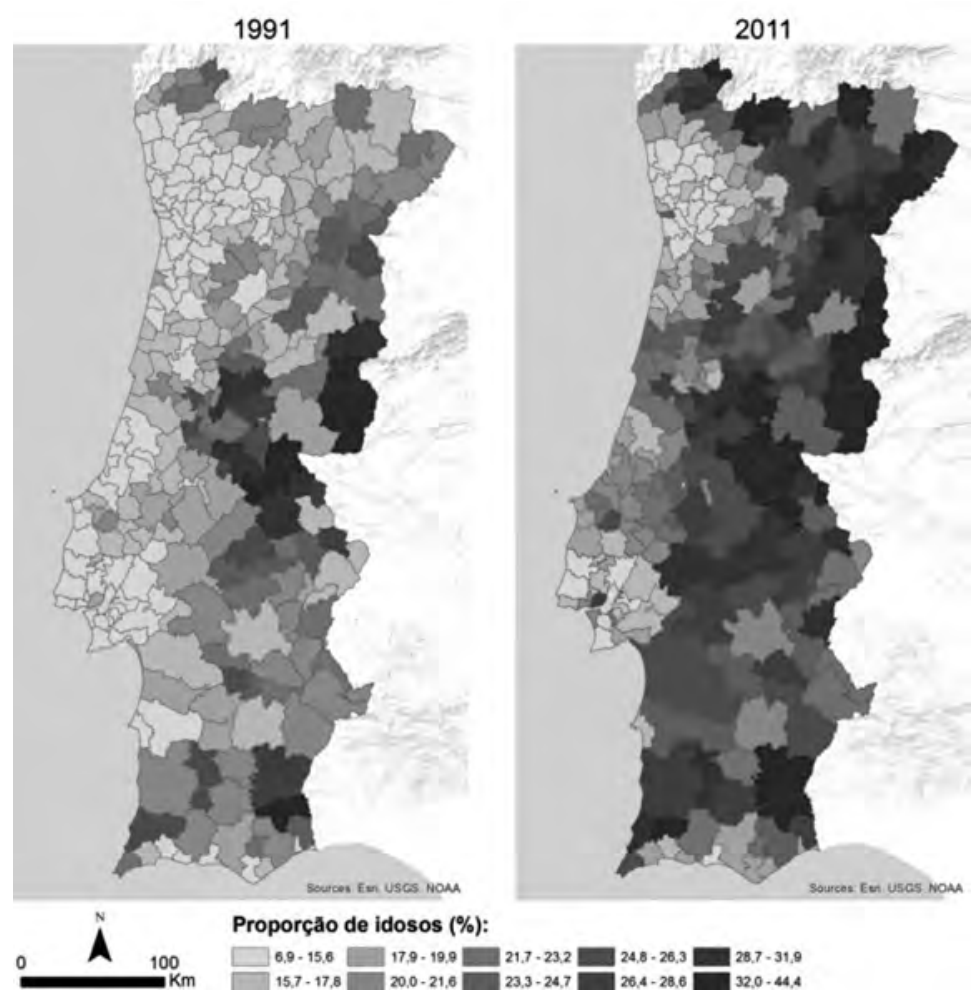

Proporçăo de idosos (\%):

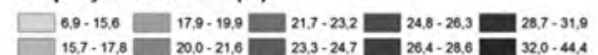

\section{Figura 4}

Proporção de idosos na população total (\%), em 1991 e 2011

Fonte: Elaborado a partir de INE, Portugal, 1991 e 2001.

Analisando o IPM (Figura 6) verifica-se que os municípios com piores resultados se localizam nas áreas rurais e mais afastadas da faixa litoral. Entre 1991 e 2011 as desigualdades entre municípios diminuíram, havendo em 2011 uma maior concentração de municípios com valores próximo de 0 e menos valores extremos (tanto altos como baixos).

Olhando também para a densidade populacional (Figura 7) verifica-se um despovoamento dos municípios do interior, principalmente do interior Centro e Sul, tendência que se acentuou de 1991 para 2011. 


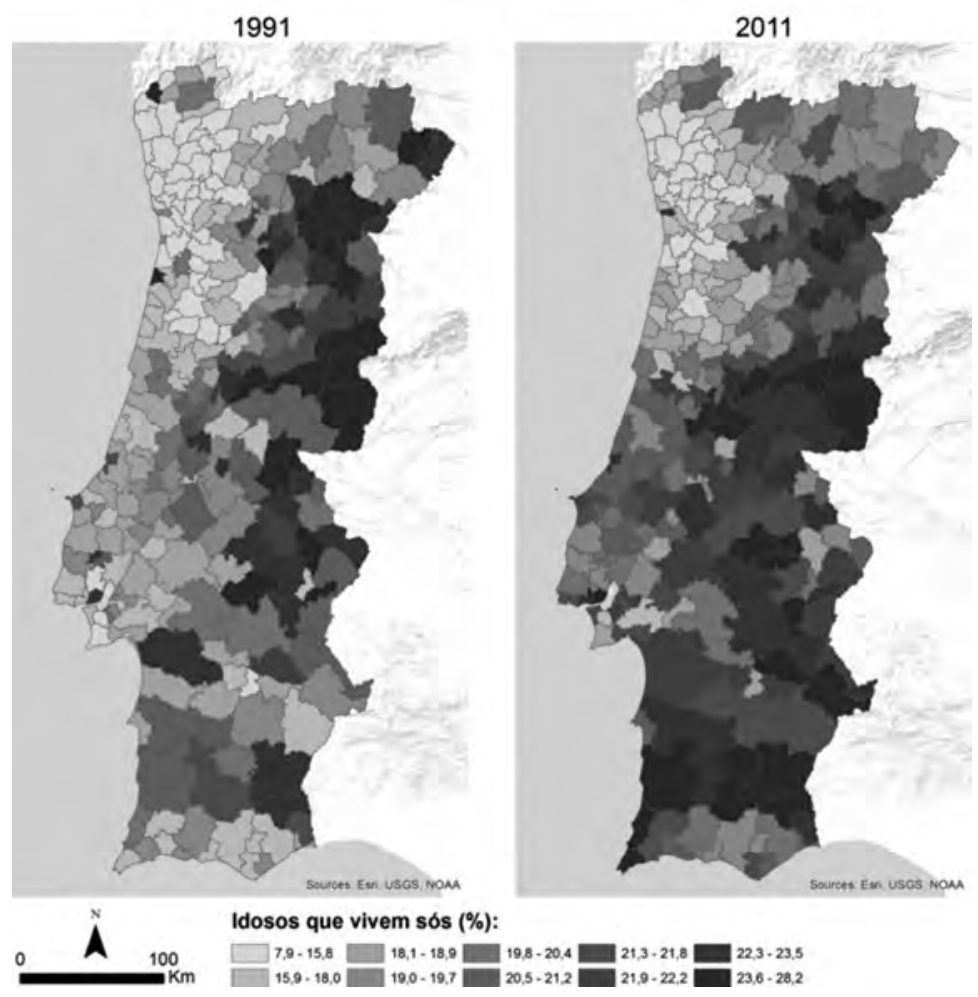

Figura 5

Idosos que vivem sós (\%), em 1991 e 2011

Fonte: Elaborado a partir de INE, Portugal, 1991 e 2001.

A observação da associação entre os quintis de IPM e os indicadores de contexto (Figura 8) permite concluir que existem fortes e significativas correlaçôes lineares entre eles. O aumento da privação material está, assim, negativamente associado à diminuição do Índice de Saúde da População e da densidade populacional. Com os restantes indicadores, a associação é positiva e estatisticamente significativa, estando maiores níveis de privação associados a uma maior mortalidade prematura, proporção de idosos, idosos a viverem sós e maior distância a hospitais. 


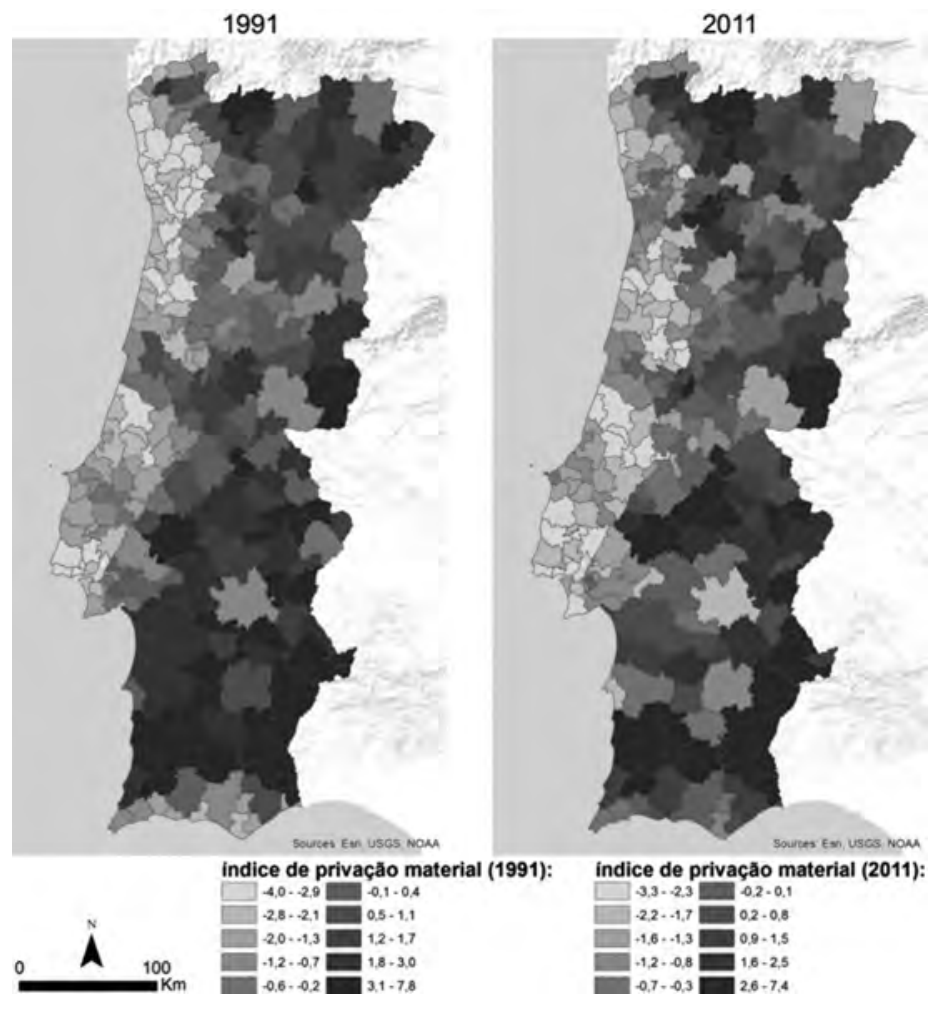

Figura 6

Índice de Privação Material, em 1991 e 2011

Fonte: Elaborado a partir de INE, Portugal, 1991 e 2001

A estatística I de Moran Global foi aplicada às variáveis selecionadas, evidenciando auto correlaçóes espaciais globais positivas $(\mathrm{p}<0,05)$ para todos os indicadores.

Analisando a sobreposição de clusters espaciais (Análise Espacial Local - LISA) de valores negativos dos indicadores de contexto apresentados anteriormente, verifica-se que em 1991 a quase totalidade dos municípios fronteiriços fazem parte de, pelo menos, um cluster, destacando-se os concelhos do Interior Norte e do Alentejo pela frequência com que foram identificados (Figura 9). Em 2011 verifica-se uma ligeira alteração do padrão, podendo observar-se uma importante melhoria dos municípios do Interior Norte. 


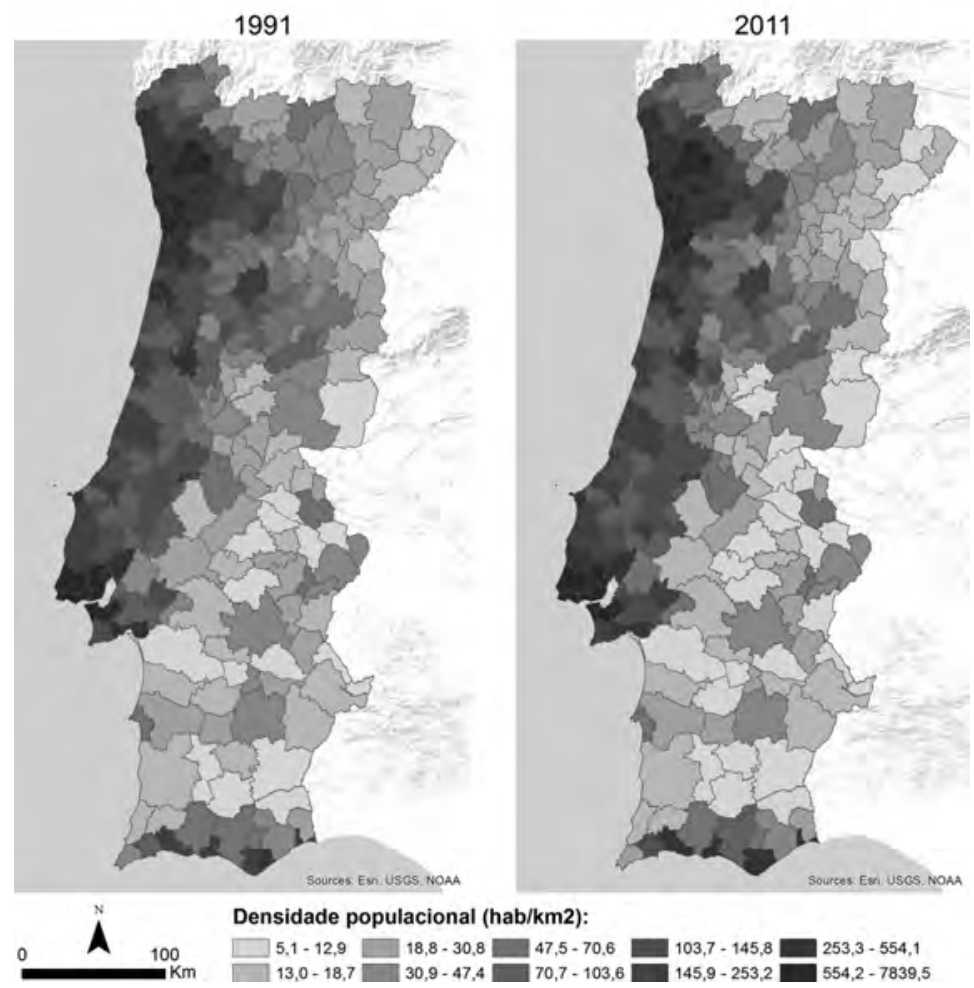

\section{Figura 7}

Densidade populacional $\left(\mathrm{hab} / \mathrm{km}^{2}\right)$, em 1991 e 2011

Fonte: Elaborado a partir de INE, Portugal, 1991 e 2001

Ao observar a sobreposição de clusters de valores positivos destaca-se a faixa litoral entre Lisboa e Minho Litoral pela frequência com que os municípios foram identificados (Figura 10). Comparando os períodos em análise, esta tendência parece intensificar-se, observando-se incremento de número de municípios, nos clusters positivos, na região Centro. 


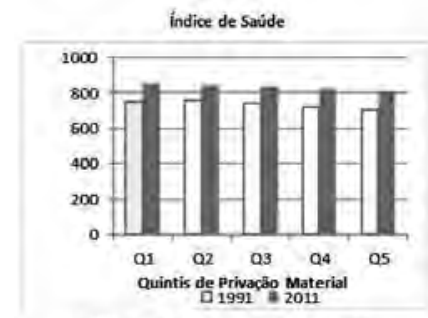

1991 - R2: 0,87 ; peorson: $-0,93(p=0,02)$ 2011 - R2:0,97; peorson: $-0,99(p=0,00)$

Proporçāo de idosos na populaçāo total (\%)

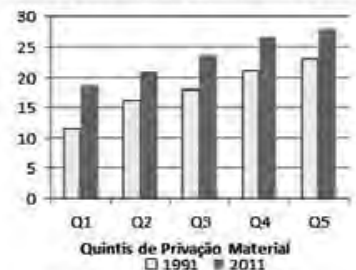

1991-R2:0,97: peorson: $0,99(0=0,00)$

2011-R2:0,99; peorsons $0,99(0-5,00)$

Acesso geográfico a hospitais (min)

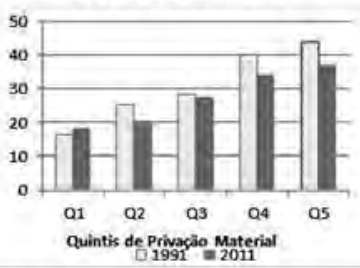

1991 - R2:0,97; peorson: $0,99(p-0,00)$

$2011-R 2: 0,97$; peorson: $0,99(p=0,00)$

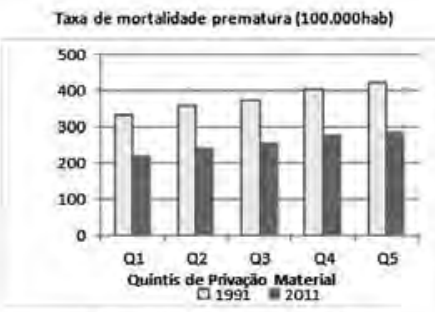

1991 - R2:0,99; peorson: $1,00(p=0,00)$

2011-R2,0,98; peorson: $0,99(p=0,00)$

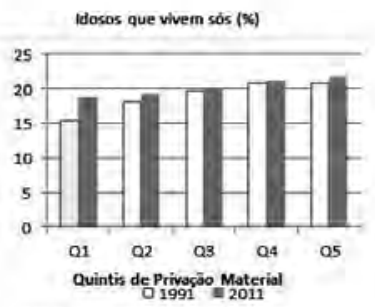

$1991-R 2: 0,89$ : peorson: $0,94 \quad(p=0,02)$

$2011-R 2: 0,98$; peorson: $0,99(p=0,00)$

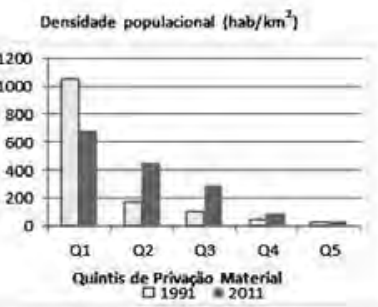

1991-R2:0,53; peorson: $-0,79(0=0,11)$

$2011-R 2: 0,97$; peorsont $-0,98(\rho-0,00)$

Figura 8

Associação entre quintis do Indice de Privação Material (Q1= baixo; Q5=alto) e as condiçốes de contexto

Fonte: Elaborado a partir de INE, Portugal, 1991 e 2001. 


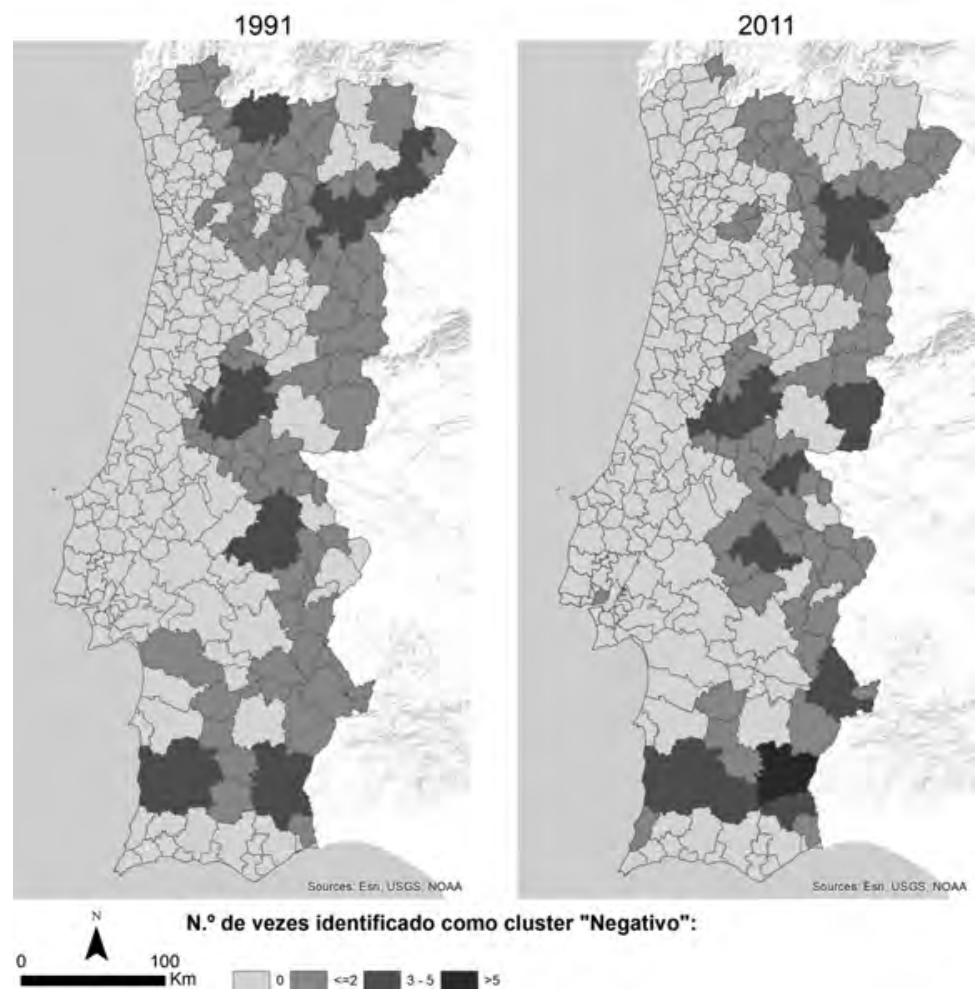

Figura 9

Sobreposição de clusters negativos, em 1991 e 2011

Fonte: Elaborado a partir de INE, Portugal, 1991 e 2001.

\section{Satisfação das USF: perfil dos utilizadores e associaçáo com as características do contexto}

Verifica-se que a satisfação dos utilizadores das USF varia consideravelmente com a idade (Figura 11). Nos grupos etários mais novos há maior percentagem de indivíduos no tercil mais baixos de satisfação (37\% dos 16 aos 34 anos e $35 \%$ dos 35 aos 54 anos). A partir desta classe etária verifica-se uma inversão de tendência, com $40 \%$ e $43 \%$ dos inquiridos entre 55 e 74 anos e com 75 e mais, 
respetivamente, a fazerem parte do tercil de maior satisfação. Comparando as diversas dimensóes da satisfaçáo identifica-se um padrão semelhante, em que os indivíduos mais novos apresentam menor satisfação em todas as dimensóes.

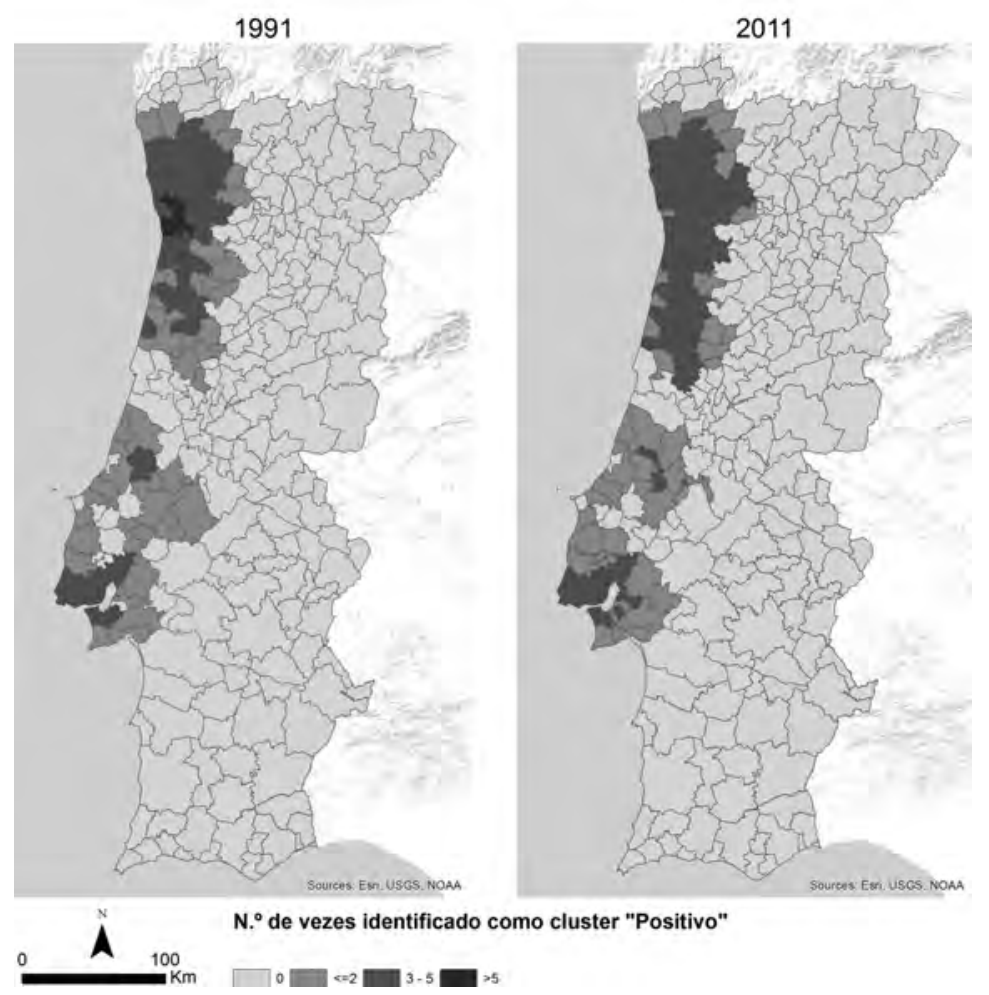

Figura 10

Sobreposição de clusters positivos, em 1991 e 2011

Fonte: Elaborado a partir de INE, Portugal, 1991 e 2001.

Relativamente ao género, os indivíduos do sexo masculino apresentam maior satisfação geral que as mulheres, sendo esta diferença mais importante na dimensão de satisfação organizacional e menos na satisfação médica e não médica. Por outro lado, indivíduos com menor formação tendem a reportar maior satisfação geral; contrariamente são os indivíduos com ensino secundário 
que indicam menor satisfação. Comparando os indivíduos com formação inferior ao ensino básico com os que possuem ensino médio ou superior verifica-se que apenas relativamente à satisfação médica apresentam valores semelhantes, em todas as outras dimensôes os inquiridos com menor formação reportaram encontrar-se mais satisfeitos.

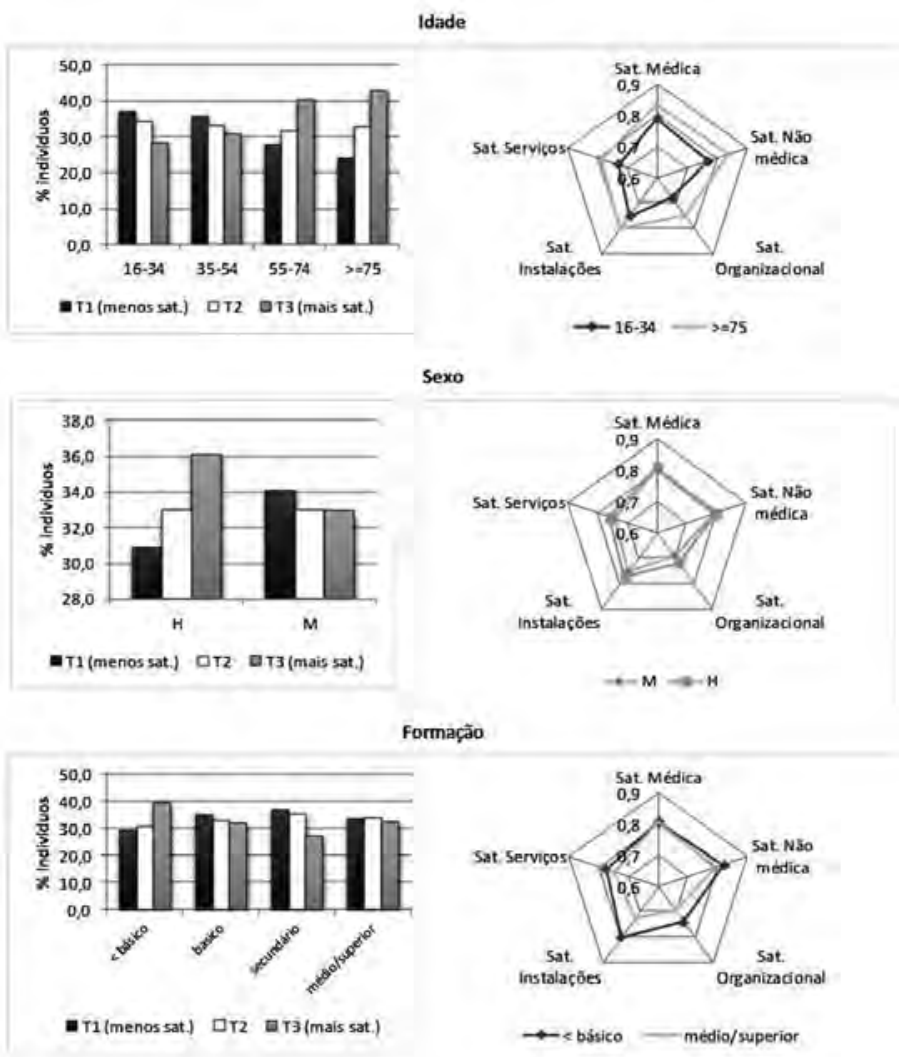

Figura 11

Satisfação dos utilizadores das USF (geral e por dimensão)

Fonte: Questionário de Satisfação aos utilizadores das USF. 
Analisando a variação dos valores médios de satisfação por quintil dos indicadores considerados (Quadro III), verifica-se que a densidade populacional, a acessibilidade geográfica aos hospitais e o Índice de saúde da população apresentam fortes correlaçôes com a satisfação (apenas a densidade populacioal regista correlação estatisticamente significativo). Maior distância aos hospitais está, assim, associada a menor satisfação; contrariamente, municípios mais densamente povoados e com melhor índice de saúde apresentam melhores resultados de satisfação média.

\section{Quadro III}

Satisfação média por quintil de condições contextuais, em 2011, e correlação linear de Pearson

\begin{tabular}{|l|c|c|c|}
\hline \multirow{2}{*}{\multicolumn{1}{|c|}{ Indicadores de contexto }} & \multicolumn{2}{|c|}{$\begin{array}{c}\text { Satisfaçáo geral média } \\
\text { por Quintil }\end{array}$} & \multirow{2}{*}{$\begin{array}{c}\text { Correlação } \\
\text { (p-value) }\end{array}$} \\
\cline { 2 - 3 } & Quintil 1 & Quintil 5 & \\
\hline Índice de privação material & 0,77 & 0,78 & $-0,25(0,71)$ \\
\hline Idosos que vivem sós & 0,77 & 0,77 & $-0,44(0,46)$ \\
\hline Proporção de idosos na população total & 0,77 & 0,79 & $0,14(0,82)$ \\
\hline Densidade populacional & 0,74 & 0,78 & $0,99(0,00)$ \\
\hline Índice de saúde da população & 0,74 & 0,78 & $0,77(0,13)$ \\
\hline Taxa de mortalidade prematura & 0,77 & 0,77 & $-0,43(0,47)$ \\
\hline Acessibilidade geográfica aos hospitais & 0,78 & 0,71 & $-0,82(0,09)$ \\
\hline
\end{tabular}

Fonte: Elaborado a partir de INE e Questionário de Satisfaçáo aos utilizadores das USF.

\section{Conclusão}

Em geral, quando se analisam as variáveis de contexto socioeconómicas, demográficas, de saúde geral e de acessibilidade, evidencia-se uma assimetria 
regional. Quando é estudada a satisfação que os utilizadores têm das unidades de prestação de cuidados de saúde primários, encontra-se também uma grande assimetria.

No entanto, quando a satisfação é comparada com as variáveis de contexto, apenas se verifica uma correlação significatica com a densidade populacional. Pode-se assim concluir que não são as condiçôes contextuais que ditam uma maior ou menor satisfação por parte dos utilizadores dos CSP. Os determinantes desta satisfação são possivelmente outras variáveis mais relacionadas com aspetos de organização interna das unidades funcionais e/ou aspetos de personalidade e de liderança dos responsáveis de tais unidades.

\section{Referências bibliográficas}

Anselin, L. (1995). Local Indicators of Spatial Association - LISA. Geographical Analysis, 27(2), pp. 93-184.

Campbell, S. M.; Roland, M. O. \& Buetow, S. A. (2000). Defining quality of care. Soc Sci Med, 51(11), pp. 1611-25.

Carstairs, V. \& Morris, R. (1990). Deprivation and health in Scotland. Health Bull (Edinb), 48(4), pp. $162-75$.

Debono. D. \& Travaglia, J. (2009). Complaints and patient satisfaction: a comprehensive review of the literature. University of New South Wales. Centre for Clinical Governance Research in Health.

Donabedian, A. (1988). The quality of care. How can it be assessed? JAMA, 260(12), pp. 1743-8.

Ferreira. P. L. \& Raposo, C. (2015). Monitorização da satisfação dos utilizadores das USF e de uma amostra de UCSP. Relatório Final. Centro de Estudos e Investgação em Saúde da Universidade de Coimbra, 2015.

Freitas, A. \& Costa C. 2015). Resultados em saúde e determinantes contextuais. In: P. Santana (coord.), A Geografia da Saúde da População. Evolução nos últimos 20 anos em Portugal Continental, pp. 8-15. CEGOT, 2015.

Grol, R.; Wensing, M.; Mainz, J.; Jung, H. P.; Ferreira, P. L.; Hearnshaw, H.; Hjortdahl, P.; Olesen, F.; Reis, S.; Ribacke, M. \& Szecsenyi, J. (2000). Patients in Europe evaluate general practice care: an international comparison. Br J Gen Pract., 50(460), pp. 882-7.

Koivusalo, M.; Wyss, K. \& Santana, P. (2007). Effects of decentralization and recentralization on equity dimensions of health systems. In R. Saltamn, V. Bankauskaite \& K. Varngbaek (eds.), Decentralization in Health Care. European Observatory on Health Care Systems, pp. 189-205. World Health Organization

Marmot, M.; Friel, S.; Bell, R.; Houweling, T. A. J. \& Taylor, S. (2008). Closing the gap in a generation: health equity through action on the social determinants of health. Lancet, 372, pp. 1661-9. 
OECD (2015). Reviews of Health Care Quality: Portugal 2015: Raising Standards, OECD Publishing, Paris.

OPSS, Sakellarides C. (coord.). Conhecer os caminhos da saúde. Relatório de Primavera 2001. Lisboa: Observatório Português dos Sistemas de Saúde; 2001.

OPSS, Sakellarides C. (coord.). O estado da saúde e a saúde do Estado. Relatório de Primavera 2002. Lisboa: Observatório Português dos Sistemas de Saúde; 2002.

OPSS, Ferreira P. L. (coord.). Sistema de saúde português: riscos e incertezas. Relatório de Primavera 2008. Coimbra: Mar da Palavra; 2008.

Santana, P. (2014). A saúde dos Portugueses. In A. Campos \& J. Simões (coord). 40 anos de Abril na saúde, pp. 68-93. Almedina, 2014.

Santana, P. \& Freitas A. (2015a) A saúde da população. Enquadramento teórico e metodológico. In: P. Santana (coord.), A Geografia da Saúde da População. Evolução nos últimos 20 anos em Portugal Continental, pp. 8-15. CEGOT, 2015.

Santana, P. \& Freitas, A. (2015b). Índice de saúde da populaçáo nos últimos 20 anos. A saúde da população. In P. Santana (coord.), A Geografia da Saúde da População. Evolução nos últimos 20 anos em Portugal Continental, pp. 80-105. CEGOT.

Vuori, H. (1987). Patient satisfaction -an attribute or indicator of the quality of care? QRB Qual Rev Bull.,13(3), pp. 106-8.

WHO (2007). Everybody's business. Strengthening health systems to improve health outcomes. Geneva, Switzerland: World Health Organization.

WHO (2000). The World Health Report 2000. Health systems: improving performance. Geneva 27, Switzerland: World Health Organization. 